\title{
A Superhydrophobic/Electrothermal/Photothermal Synergistically Anti-icing Strategy with Excellent Self-healable and Anti-abrasion Property
}

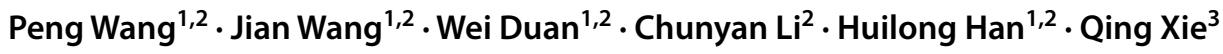

Received: 14 August 2020 / Revised: 23 July 2021 / Accepted: 29 July 2021 / Published online: 30 September 2021

(c) The Author(s) 2021

\begin{abstract}
Unexpected ice accumulation tends to cause many problems or even disasters in our daily life. Based on the superior electrothermal and photothermal function of the carbon nanotubes, we introduced a superhydrophobic/electrothermal/photothermal synergistically anti-icing strategy. When a voltage of $15 \mathrm{~V}$ was applied to the superhydrophobic sample, the surface could rapidly melt the ice layer $\left(\sim 3 \mathrm{~mm}\right.$ thickness) within $530 \mathrm{~s}$ at the environmental temperature of $-25{ }^{\circ} \mathrm{C}$. When the near-infrared light $(808 \mathrm{~nm})$ irradiates on the superhydrophobic sample, the ice could be rapidly removed after $460 \mathrm{~s}$. It was found that the superhydrophobicity helps the melted water to roll off immediately, and then solves the re-freeze problem the traditional surfaces facing. Moreover, the ice can be completely melted with $120 \mathrm{~s}$ when the superhydrophobic/electrothermal/ photothermal synergistically anti-icing strategy was utilized. To improve the mechanical robustness for practical application, both nanoscale carbon nanotubes and microscale carbon powders were utilized to construct hierarchical structure. Then these dual-scale fillers were sprinkled onto the semi-cured elastomer substrate to prepare partially embedded structure. Both hierarchical structure and partially embedded structure were obtained after completely curing the substrate, which imparts excellent abrasion resistance $(12.50 \mathrm{kPa}, 16.00 \mathrm{~m})$ to the prepared sample. Moreover, self-healable poly(urea-urethane) elastomer was introduced as the substrate. Thus, the cutted superhydrophobic sample can be mended by simply contacting at room temperature.
\end{abstract}

Keywords Superhydrophobic $\cdot$ Electrothermal $\cdot$ Photothermal $\cdot$ Self-healing

\section{Introduction}

The accumulation of ice tended to create life-threatening hazards in our daily life [1]. For instance, the ice accretion will generate extra weight which increases the burden of aircraft [2]; the ice formation between umbrella skirts

Peng Wang

wangpeng1986@ncepu.edu.cn

Qing Xie

xq_ncepu@126.com

1 School of Energy, Power and Mechanical Engineering, North China Electric Power University, Baoding, China

2 Hebei Key Laboratory of Electric Machinery Health Maintenance and Failure Prevention, North China Electric Power University, Baoding 071003, China

3 School of Electrical and Electronic Engineering, North China Electric Power University, Baoding, Hebei, China of the insulator in power line will generate new conductive path which tends to cause flashover [3]. Many methods have been introduced for anti-icing/de-icing, such as heating [4], releasing anti-icing agent [5], liquid-infused materials [6], and superhydrophobic surfaces [7]. Among these methods, the passive anti-icing method inspired by superhydrophobic surfaces has garnered considerable attention due to their advantages of energy-saving and high efficiency [8,9].

A typical superhydrophobicity can be found in the lotus leaves in nature. The water droplets exhibit a nearly round shape on the surface of lotus leaves, and roll off easily under a tiny sliding angle [10]. The further studies reveal that the combination of low surface energy and suitable micro/nano-structure can capture air pockets between the interfaces, which lead to superhydrophobicity. Furthermore, it is found that the air pockets underneath the water droplets or ice could effectively delay freezing time and decrease the adhesion force [11]. Nevertheless, the 
superhydrophobic surface can only delay the formation of the ice. The accumulation of ice in the long-lasting terrible weather is still inevitable, such as the 2008 freezing rain accident in China [12].

To overcome this obstacle, the researches tried to combine the superhydrophobic materials with active de-icing technology. One research direction is to integrate the superhydrophobicity with joule heating method. For instance, Chen et al. prepared superhydrophobic conductive paper based on ketjen black and polyethylene, which could remove the ice using the electrothermal and non-adhesive performance [13]. Jiao et al. fabricated superhydrophobic film using reduced graphene oxide wrinkles, which demonstrated excellent de-icing property [14]. Another research direction is to integrate the superhydrophobicity with photothermal effect. For example, Jiang et al. fabricated $\mathrm{SiC} /$ carbon nanotube superhydrophobic coating, which demonstrated high light-to-heat conversion efficiency [15]. Therefore, A superhydrophobic/electrother$\mathrm{mal} /$ photothermal synergistically anti-icing strategy will further improve the de-icing efficiency.

The biggest drawback of superhydrophobic materials is the poor mechanical robustness, which prohibits the practical application. Most superhydrophobic materials are fragile to sandpaper abrasion, or even finger contact $[16,17]$. Kulinich et al. further found that the cyclic icing/de-icing process tended to damage the surface structure of superhydrophobic materials which led to lose of icephobicity [18]. To improve the mechanical robustness, Parkin et al. invented a "Paint + Adhesive" method [19]. By bonding the $\mathrm{TiO}_{2}$ nanoparticles with the commercial adhesive, the superhydrophobic coating exhibited a maximum abrasion distance of $8.00 \mathrm{~m}$ under a $100 \mathrm{~g}$ load. Guo et al. utilized the inorganic adhesive to bond the $\mathrm{SiO}_{2}$ nanoparticles, and the prepared surfaces maintained superhydrophobicity after being abraded for $10.00 \mathrm{~m}$ under a $200 \mathrm{~g}$ load [20]. In our previous work, we prepared abrasion-resistant superhydrophobic transparent coating by partially embedding the silica nanoparticles into the PDMS matrix [21]. Meanwhile, Ras et al. introduced hierarchical structure which attempted to use the relatively robust microstructure to guard the fragile nano-structure [22]. Nevertheless, the superhydrophobic materials prepared by the aforementioned methods could not withstand severe mechanical damage, such as wide and deep scratches.

When we accidentally broken our skin, the wound could be spontaneously repaired in our daily life. In fact, the capability to repair damaged organisms is a fundamental function for the living organisms. Inspired by this phenomenon, many kinds of self-healable materials have been prepared by the introduction of reversible or exchangeable bonds [23]. Recently, Sun et al. fabricated self-healable superhydrophobic film by drop-casting Ag nanowires onto the healable film [24]. In this research, we tried to partially embed micro-scale carbon powders and nanoscale carbon nanotubes into healable elastomer. The base elastomer endows this composite self-healable function, and the fluoroalkyl-silane modified dual-scale carbon materials endow the composite superhydrophobic/ electrothermal/photothermal properties simultaneously. The further anti-icing test demonstrated the superiority of this superhydrophobic/electrothermal/photothermal synergistically anti-icing strategy. Furthermore, the as-prepared materials combined the partially embedded and hierarchical structure, which maintained superhydrophocity even after abraded for $16.00 \mathrm{~m}$ under a load of $500 \mathrm{~g}$.

\section{Materials and Methods}

\subsection{Materials}

Trifunctional poly (propylene glycol) $(\mathrm{PPG}, \mathrm{Mn}=6000)$ was bought from Bayer Materials Science. The PPG with low molecular weight $(330 \mathrm{~N})$ was purchased from Jining Huakai Resin Co., Ltd., China. 1H, 1H, 2H, 2H-perfluorooctyltriethoxysilane $\left(\mathrm{C}_{8} \mathrm{~F}_{13} \mathrm{H}_{4} \mathrm{Si}\left(\mathrm{OCH}_{2} \mathrm{CH}_{3}\right)_{3}\right.$, FAS $)$, 4-Aminophenyl disulfide (APS, 98\%), isophorone diisocyanate (IPDI, 99\%), tetrahydrofuran (THF, 99\%), and carbon powder ( $\geq 200$ mesh) were purchased from Aladdin Reagent Co., Ltd, Shanghai, China. The dibutyltin dilaurate (DBTDL, 95\%) was purchased from Sinopharm Chemical Reagent Co., Ltd., Shanghai, China. The multiwall carbon nanotubes (MWCNTs) with an average diameter of $30 \mathrm{~nm}-50 \mathrm{~nm}$ (TNM7, $\geq 98 \%$ purity) were bought by Chengdu Organic Chemicals Co., Ltd., China. All chemicals were used as received.

\subsection{The Synthesis of Prepolymer A}

The prepolymer A was synthesized based on reference [25] with some modification. First, the PPG 6000 (39 g, $65 \mathrm{mmol}$ ) was poured into a $500 \mathrm{~mL}$ four-necked flask equipped with a mechanical stirrer and a vacuum inlet. Then, the PPG 6000 was stirred under vacuum at $120^{\circ} \mathrm{C}$ for $1 \mathrm{~h}$ to remove residual moisture. After cooling the temperature to $70{ }^{\circ} \mathrm{C}$, IPDI $(4.545 \mathrm{~g}, 204.5 \mathrm{mmol})$ was added, and the mixture was stirred under vacuum at $70{ }^{\circ} \mathrm{C}$ for $10 \mathrm{~min}$. Finally, DBTDL ( $2 \mathrm{mg}$ ) was added, and the mixture was further heated at $70{ }^{\circ} \mathrm{C}$ for $45 \mathrm{~min}$ under vacuum and stirring to obtain prepolymer A.

\subsection{The Synthesis of Prepolymer B}

First, PPG330N ( $25 \mathrm{~g}, 125 \mathrm{mmol})$ was poured into a $500 \mathrm{~mL}$ four-necked flask, and heated at $120{ }^{\circ} \mathrm{C}$ under stirring and vacuum for $1 \mathrm{~h}$ to remove internal moisture. After the 
temperature was cooled to $60{ }^{\circ} \mathrm{C}$, IPDI $(5.55 \mathrm{~g}, 250 \mathrm{mmol})$ was added. Then, the mixture was stirred under vacuum at $60{ }^{\circ} \mathrm{C}$ for $10 \mathrm{~min}$. In the next step, $1.5 \mathrm{mg}$ of DBTDL was added. Finally, the mixture was further stirred under vacuum at $60{ }^{\circ} \mathrm{C}$ for $70 \mathrm{~min}$ to obtain prepolymer B.

\subsection{Preparation of Hydrophobic CNT Powders}

First, $0.3 \mathrm{~g}$ of FAS was dissolved in $25 \mathrm{~g}$ of THF, and the solution was magnetically stirred for $2 \mathrm{~h}$. Then, $1 \mathrm{~g}$ of MWCNTs were added to the solution. To ensure the dispersion of MWCNTs, the mixture was ultrasonic treated for $1 \mathrm{~h}$ and then magnetically stirred for $6 \mathrm{~h}$. Finally, the mixture was placed in a vacuum drying box. After vacuum drying, the hydrophobic MWCNT powders were collected.

\subsection{Preparation of Hydrophobic CNT Solution}

First, $0.4 \mathrm{~g}$ of FAS was dissolved in $30 \mathrm{~g}$ of THF, and the solution was magnetically stirred for $2 \mathrm{~h}$. In the next step, $1 \mathrm{~g}$ of carbon powders was added to the solution. Then, the mixture was magnetically stirred at room temperature for $6 \mathrm{~h}$ to obtain uniform hydrophobic CNT solution.

\subsection{Preparation of Self-healing Superhydrophobic Coating}

First, the prepolymer (A) and the prepolymer (B) were mixed in a $100 \mathrm{~mL}$ glass container. Then, a solution of 4-Aminophenyl disulfide (20.6 mmol) in THF ( $3 \mathrm{~mL}$ ) was added, and the mixture was mechanically stirred to obtain self-healing polymer $\mathrm{C}$. In the next step, the mixture was poured into a tetrafluoroethylene mold and degassed for $20 \mathrm{~min}$ in a vacuum environment to remove bubbles. Then, hydrophobic carbon powders were uniformly sprinkled on the surface of polymer $\mathrm{C}$ with the help of a copper mesh (200 mesh). After further heating the sample at $70{ }^{\circ} \mathrm{C}$ for $3 \mathrm{~h}$, the polymer $\mathrm{C}$ was semi-cured. Then, the hydrophobic CNT solution was sprayed onto the sample to improve the conductivity. Finally, the self-healing superhydrophobic sample was fabricated by removing the sample from the mold after $24 \mathrm{~h}$.

\subsection{Characterization}

The Scanning Electron Microscope (SEM, TESCAN Vega3) was utilized to measure the surface morphology. X-ray Photoelectron Spectroscopy (XPS, Thermo ESCALAB 250XI, USA) was adapted to detect the samples' chemical composition. We further measured the water Contact Angles (CAs) and Sliding Angles (SAs) in term of JC2000D (Shanghai Zhongchen, China) apparatus. At least five positions were measured for each sample, and the average values were calculated. The dynamic bouncing test was investigated by the means of high-speed camera (Revealer 2F04).

\subsection{Icing/De-icing Test}

The icing/de-icing tests are based on references $[15,26]$ with some minor modifications. During all the icing/deicing process, a digital microscope (Andonstar-A1, China) was adopted to observe the freezing process and then determine the freezing time. Moreover, an infrared imager (FLIR-C2, FLIR Ltd., USA) was used to measure the surface temperature.

For the freezing test of a droplet, the samples were put into the climate chamber (temperature: $-25{ }^{\circ} \mathrm{C}$, relative humidity: $30 \%$ ). Then, a $5 \mu \mathrm{L}$ water droplet was carefully put onto the sample surface using a syringe.

For the glaze ice test, the samples were put into the climate chamber at the temperature of $-25^{\circ} \mathrm{C}$ and the relative humidity of $80 \%$. A commercial moisturizer was also put onto the climate chamber and served as the generator of water droplets. Then, $1 \mathrm{~L}$ of supercool water $\left(\sim 0^{\circ} \mathrm{C}\right)$ was put into a commercial moisturizer. With the help of moisturizer, a large amount of microscale water droplets could be generated and fell onto the surface of samples.

For the electrothermal (ET) de-icing test, the moisturizer stopped work and a Direct Current (DC) voltage of $15 \mathrm{~V}$ was applied to generate Joule heating. For the photothermal (PT) de-icing test, the near-infrared laser $(808 \mathrm{~nm}$, Model NO. LSR808H-FC-1 W, Lasever Inc., Ningbo, China) was utilized to irradiate the surface of sample. For the ET/PT synergistically de-icing test, both DC resource $(15 \mathrm{~V})$ and near-infrared laser worked to accelerate the melt of the ice.

\section{Results and Discussion}

\subsection{The Morphology and Chemical Composition}

Here, the keypoint is to achieve self-healing function and mechanical robustness simultaneously, which was achieved by partially embedding hierarchical structure into a selfhealing substrate (Fig. 1a). Both microscale filler (carbon powder, $10 \mu \mathrm{m}-100 \mu \mathrm{m}$ size) and nanoscale filler (MWCNT, $30 \mathrm{~nm}-50 \mathrm{~nm}$ diameters) were utilized in this research. Because of the dual-scale nature of the fillers, the hierarchical structure would be constructed by sparsing the fillers onto the substrate. By further sparsing the filler onto the semi-cured substrate, the partially embedded structure could be obtained which has been confirmed by our previous research [21]. Here, the poly(urea-urethane) elastomer was 


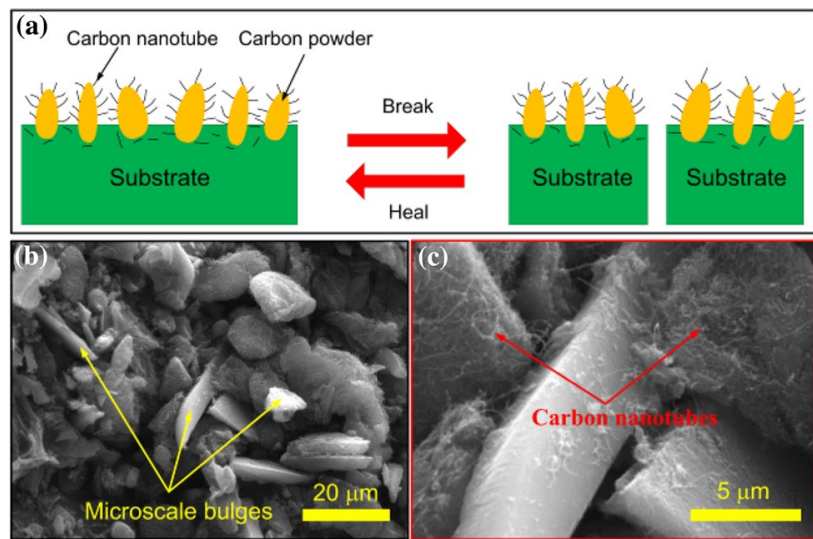

Fig. 1 a The schematic of the self-healing superhydrophobic sample. SEM images of superhydrophobic sample at $\mathbf{b}$ low and $\mathbf{c}$ high magnifications, respectively

chosen due to its excellent self-healing function. Therefore, the hierarchical structures together with partially embedded structure lead to mechanical robustness, and the self-healing substrate endows the sample healable function.

The hierarchical structure can be confirmed by the SEM observation. Many microscale bulges could be found in Fig. 1b, c. We attributed these to the carbon powders. Moreover, it was found that some CNTs were on top and between the microscale bulges (Fig. 1c). The CNTs play a vital role in the sample, which not only favors the construction of the hierarchical structure, but also favors the formation of conductive network [27, 28].

The low surface energy is another indispensable factor for preparing superhydrophobic materials. Here, we analyzed the surface chemical composition using the XPS test. From Fig. 2a, Si 2p, C 1s, O 1s, and F 1s peaks were detected. From the F 1s core-level spectra (Fig. 2b), a dominant peak at $689.2 \mathrm{eV}$ was measured. We ascribed this to the fluorine bond as $\mathrm{CF}_{x}$, which indicates that $\mathrm{F}$ is present in same bonding environment as that of FAS [29, 30]. In the case of Si $2 p$ spectrum (Fig. 2c), the raw data could be further fitted to two peaks, which are ascribed to $-\mathrm{Si}-\mathrm{OH}$ or $\mathrm{Si}-\mathrm{Fx}$ species at $104.5 \mathrm{eV}$ and $\mathrm{SiO}_{2}$-based network at $103.4 \mathrm{eV}$ [31]. Moreover, the C 1s (Fig. 2d) spectrum can be deconvoluted into five peaks at $284.80 \mathrm{eV}$, $285.90 \mathrm{eV}, 286.86 \mathrm{eV}, 292.11 \mathrm{eV}$, and $294.16 \mathrm{eV}$, which can be assigned to the $-\mathrm{CH}, \mathrm{C}-\mathrm{O}, \mathrm{C}-\mathrm{CF},-\mathrm{CF}_{2}$, and $-\mathrm{CF}_{3}$, respectively $[32,33]$. In this research, the $\mathrm{C}-\mathrm{CF},-\mathrm{CF}_{2}$, and $-\mathrm{CF}_{3}$ groups offer low surface energy, which is crucial for the formation of superhydrophobicity [34]. Then, this superhydrophobic sample demonstrates outstanding self-cleaning function. The EDS mapping analysis was further performed to confirm the element distribution. As shown in Fig. S1, this superhydrophobic sample contains $\mathrm{Si}, \mathrm{F}, \mathrm{C}$, and $\mathrm{O}$ element uniformly (Fig. S1). As shown in
Movie S1, the surface of the superhydrophobic sample was clean and dry, because the water droplets could leave the surface completely and carry the contaminants away. On the other hand, the water droplets could not leave the surface of bare glass and RTV (room-temperature vulcanized silicone rubber) coated glass, which led to dirty and wet surfaces (Movie S2-S3).

\subsection{The Self-healing Ability}

This superhydrophobic sample has advantages in restoring the loss of superhydrophobicity caused by cutting, as shown in Movie S4. Here, the original sample with a contact angle of $162.5^{\circ}$ and a sliding angle of $4.3^{\circ}$ was cut in half using scissors (Fig. 3b). Then, we mended the sample by simply contacting the cutted parts at room temperature (Movie S4 and Fig. 3d). After $1 \mathrm{~h}$ of contact, the water droplets rapidly roll off from mended sample (Movie S4). The CA and SA of the mended sample were measured to be $158.7^{\circ}$ and $6.3^{\circ}$ respectively, which indicates that the superhydrophobicity was retained. Moreover, the mended sample demonstrates excellent mechanical properties, which could withstand the weight of $500 \mathrm{~g}$ (Movie S4). The further SEM observation confirmed that the cutted polymers contact with each other again (Fig. 4). Therefore, the self-healing mechanism can be ascribed to the covalent bonds caused by the aromatic disulfide metathesis.

\subsection{The Anti-icing Ability}

In this research, both microscale carbon powders and nanoscale CNTs were utilized as the fillers. All of them have been widely studied as thermal heater for efficiently transforming electrical energy into Joule heating energy. To investigate the electrothermal property, a hybrid carbon coating ( $25 \mathrm{~mm} \times 16 \mathrm{~mm}$ size) was connected to a source of direct current (DC). Then, we detected the time-dependent temperature profile under different DC voltage using an infrared imager (Fig. 5a). It could be found that the hybrid carbon coating could attain a saturation temperature of $14.9{ }^{\circ} \mathrm{C}$ from subzero temperature $\left(-5.0^{\circ} \mathrm{C}\right)$ after applying $9 \mathrm{~V}$ voltage. Moreover, the surface temperature could increase rapidly from -5.0 to $74.6{ }^{\circ} \mathrm{C}$ under a voltage of $15 \mathrm{~V}$ (Fig. 5b).

The superior electrothermal (ET) property together with superhydrophobicity endows a unique anti-icing ability to the hybrid carbon coating. We first investigated the removing ability of the frozen droplet. A droplet $(\sim 5 \mu \mathrm{L})$ was carefully placed on the sample, and gradually frozen under $-25{ }^{\circ} \mathrm{C}$ temperature (Movie S5). Then, a voltage of $15 \mathrm{~V}$ was applied. From Fig. 6a and Movie S6, the frozen water droplet can be melted after $\sim 148 \mathrm{~s}$, and then rolled off completely without any residue. It is worth noting that 

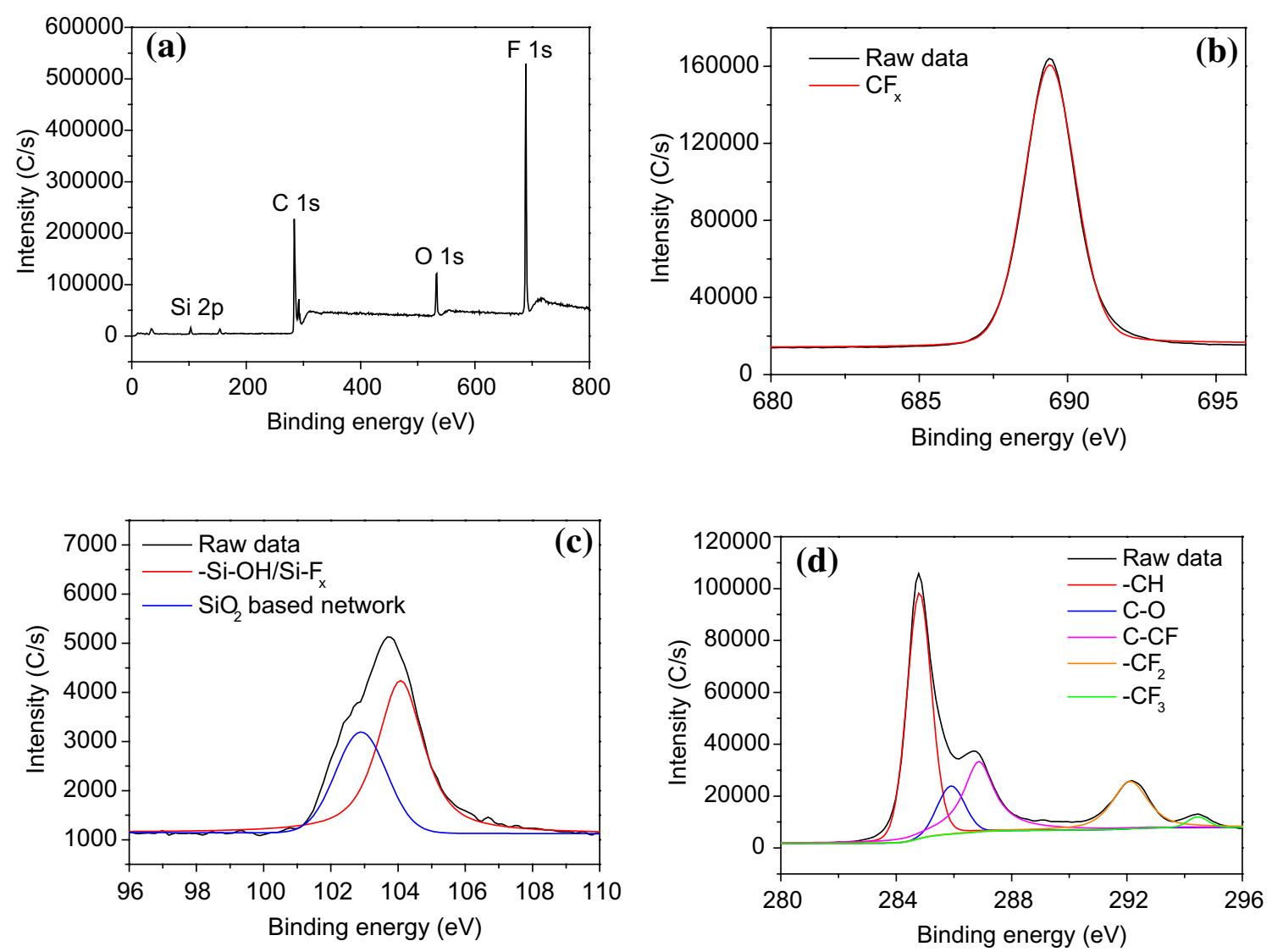

Fig. 2 a Survey XPS spectrum of the hybrid carbon coating; b F 1s, c Si 2p, and d C 1s XPS spectrum of the hybrid carbon coating

the environment temperature of de-icing test was set to be $-25^{\circ} \mathrm{C}$. Thus, the time required to melt the ice is relatively long. Besides the electrothermal effect, the photothermal

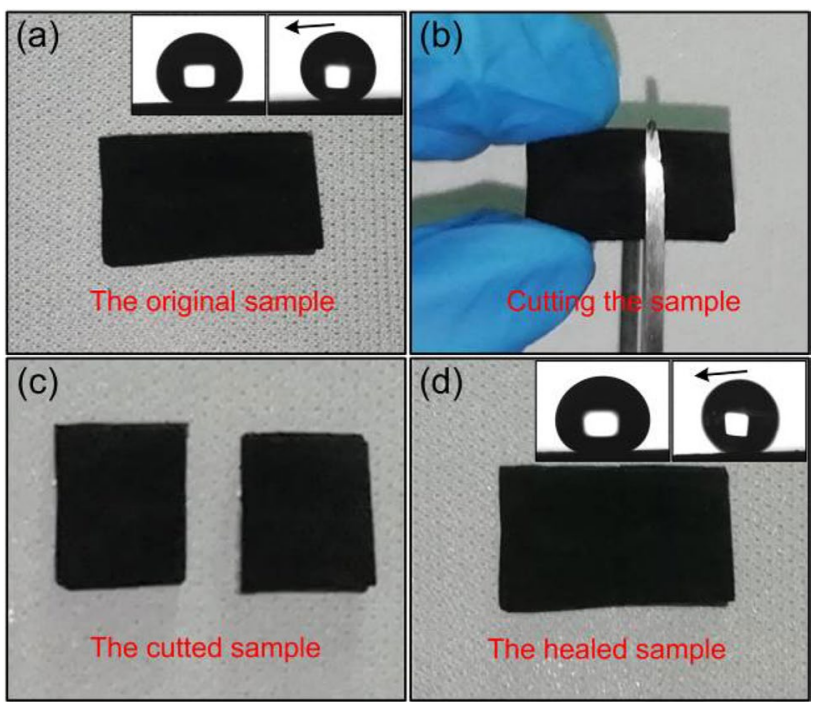

Fig. 3 The self-healing process of the superhydrophobic sample
(PT) performance of the carbon-based materials was also attracting more and more attention. Recently, He et al. prepared superhydrophobic surfaces based on candle soot, which can rapidly melt the accumulated frost and ice in $300 \mathrm{~s}$ under $1 \mathrm{~kW} \cdot \mathrm{m}^{-2}$ [35]. Here, we tried to investigate the photothermal effect of the hybrid carbon coating using the near-infrared laser ( $1 \mathrm{~W})$. Within 265 s of illumination, the frozen droplet on the hybrid carbon coating melted (Fig. 6b). The detailed de-icing process could also be found in Movie S7.

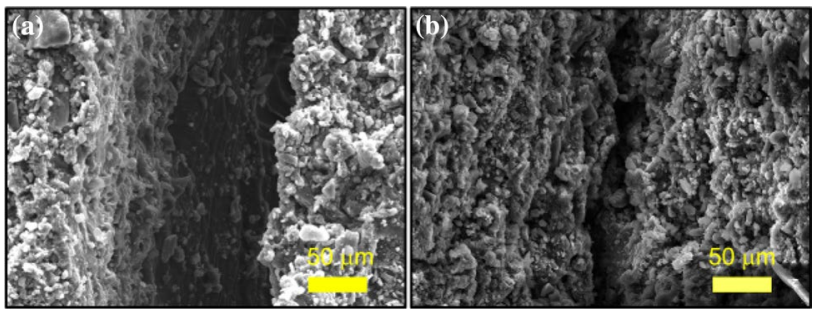

Fig. 4 The SEM image of a cutted superhydrophobic sample and $\mathbf{b}$ mended superhydrophobic sample 


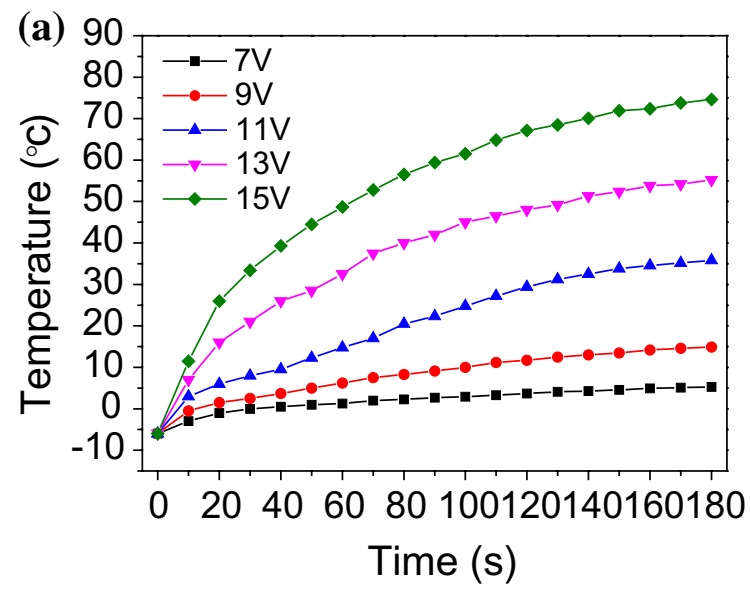

(b)

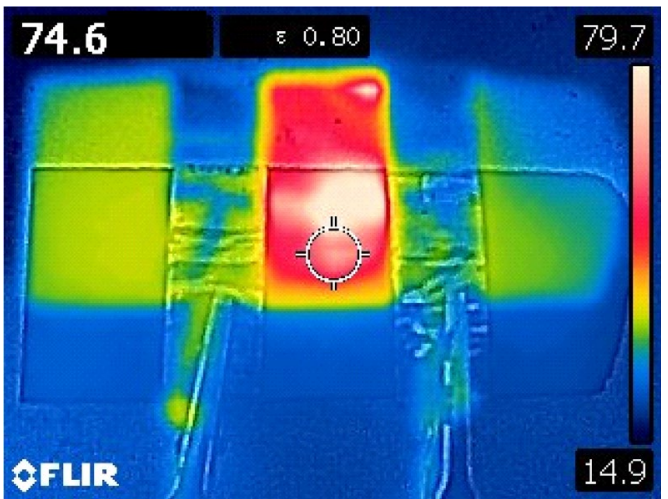

Fig. 5 a The time-dependent temperature profile of the hybrid carbon coating under different voltages. $\mathbf{b}$ The surface temperature of the hybric carbon coating under $15 \mathrm{~V}$ after $180 \mathrm{~s}$

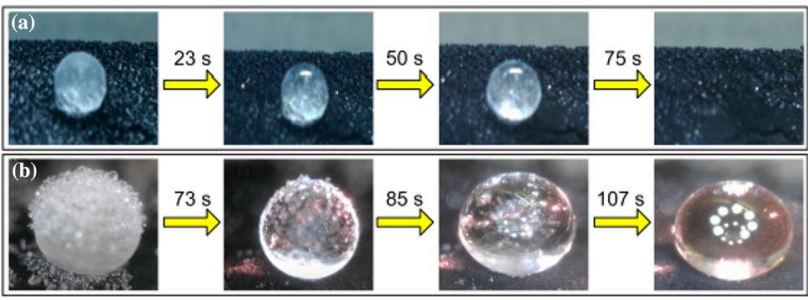

Fig. 6 a The image of electrothermal de-icing process; $\mathbf{b}$ the image of photothermal de-icing process of a frozen droplet

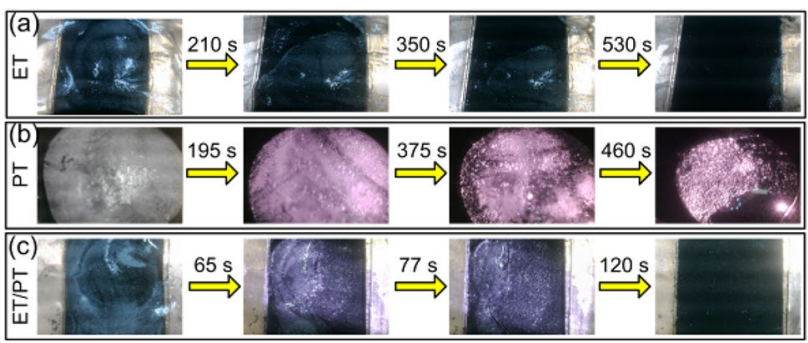

Fig. 7 a The electrothermal (ET) de-icing process; b the photothermal (PT) de-icing process; $\mathbf{c}$ the ET/PT synergistically de-icing process of an thick ice layer

Nevertheless, the de-icing process of frozen droplet cannot completely reflect the actual freezing weather. Recently, Jiang et al. systematically analyzed the surface icing accidents and found that the glaze ice is the most dangerous situation [36]. In this research, we prepared the glaze ice in the artificial climate chamber following the methods shown in reference $[15,26]$ with some small modifications. As shown in Fig. S2, an ice layer $(\sim 3 \mathrm{~mm}$ thick) was frozen on the surface of the hybrid carbon coating.
It is worth noting that CNTs are a kind of fascinating material which demonstrates excellent electrothermal (ET) and photothermal (PT) properties simultaneously. Here, the ET, PT, and ET/PT de-icing tests were all investigated and compared. We first applied a voltage of $15 \mathrm{~V}$ onto the hybrid carbon coatings. The ET effect led to the fast rise of the surface temperature, which further melted the ice (Fig. 7a). As shown in Movie S8, it takes $530 \mathrm{~s}$ for the ice layer to be completely melted. In the next step, a near-infrared laser was utilized to irradiate the surface. The carbon-based materials would absorb the near-infrared light, and the heat was generated. As shown in Movie S9, all of the ice on the hybrid carbon coating melted, and the water droplets rolled off, leaving a dry and clean surface after $460 \mathrm{~s}$ (Fig. 7b). Finally, the ET/ PT synergistically de-icing strategy was investigated. We let the DC current resource and the near-infrared laser worked at the same time. The heat generated from ET and PT could be accumulated, which would effectively speed up the de-icing time (120 s), as shown in Fig. 7c and Movie S10.

\subsection{The Mechanical Robustness}

Although superhydrophobic materials demonstrated exciting performance in self-cleaning, anti-icing, oil-water separation, and so on, most of them can be easily destroyed by a slight scratch, rubbing, and even finger contact [37-41]. Thus, the poor mechanical robustness has been regarded as Achilles' heel which prohibited the practical applications of the superhydrophobic materials. With the development of mechanical robust superhydrophobic materials, the sandpaper-abrasion test has been regarded as the most widely used method. Ras et al. further pointed out that the abrasion distance and applied 
Fig. 8 a, b Image of sandpaperabrasion process; $\mathbf{c}$ plot of CAs and SAs after each abrasion cycle

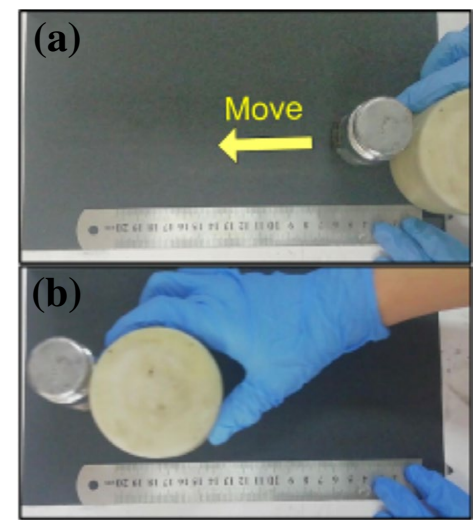

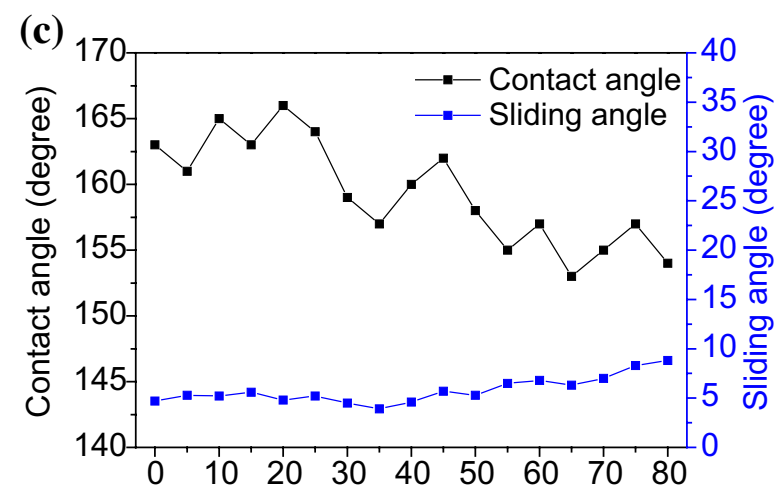

Number of abrasion cycles under $500 \mathrm{~g}$ weight normal pressure were two crucial indicators for the convenience of comparison [42]. Furthermore, Kulinich et al. found that repetitive icing/de-icing would gradually destroy the micro/nano-structure of the superhydrophobic surfaces, and then led to the loss of ice-repellence [18]. Therefore, sandpaper-abrasion test and cyclic icing/ de-icing test of the hybrid carbon coating were investigated in the research.

First, commercial sandpaper (Starcke 200\#, Germany) was utilized in the sandpaper-abrasion test. The hybrid carbon coating was coated onto an Al substrate as the sample. Then, the sample was placed on the sandpaper under a weight of $500 \mathrm{~g}$ and moved for $20 \mathrm{~cm}$ as one cycle (Fig. 8a, b). A gradual decrease in the contact angles and increase in sliding angles could be observed with the increase of abrasion cycles (Movie S11 and Fig. 8c). We attributed this to two factors: (1) some micro/nano-fillers on the surface were abraded, which might change the surface morphology; (2) the destruction of surface chemistry during the abrasion process. Nevertheless, the contact angles and sliding angles were still in the range of superhydrophobicity after 80 abrasion cycles, indicating the relatively strong mechanical robustness (abrasion distance: $16.00 \mathrm{~m}$, applied pressure: $12.50 \mathrm{kPa}$ ). We attribute the aforementioned abrasionresistant superhydrophobicity to our collaborative strategy of hierarchical structure and partially embedded structure.
As shown in Fig. 9a, some microscale bulges still exists after sandpapaer abrasion. Then, it can be concluded that the microscale bulges in the research were relatively strong which could protect the nano-fillers from being abraded. Furthermore, the scratch can be found on the surface of the sample. From the high-magnification SEM image (Fig. 9c), the micro/nano-structure made of CNT and microscale particle can be found. In this research, the nano-fillers were fully embedded or partially embedded into the substrate. Even though the exposed part was abraded, the new exposed part still has similar surface structure and then retained superhydrophobicity.

As a second mechanical robustness test, the repetitive icing/ de-icing test was further investigated. Here, a layer of glaze ice ( $\sim 3 \mathrm{~mm}$ thickness) was formed on the surface of the hybrid carbon coating. We first applied a voltage of $15 \mathrm{~V}$ for electrothermal de-icing. Then, the time required to completely melt the ice was recorded (Fig. 10a). After fully removing the ice, the surface temperature, contact angles, and sliding angles were measured (Fig. 10a, b). As shown in Fig. 10a, the deicing time gradually increased from $530 \mathrm{~s}$ to $554 \mathrm{~s}$, and the surface temperature gradually decreased from $69.0{ }^{\circ} \mathrm{C}$ to $65.9{ }^{\circ} \mathrm{C}$. Furthermore, 30 icing-de-icing cycles led to a gradual drop in contact angle from $163^{\circ}$ to $152^{\circ}$, and a tiny increase of sliding angle from $4^{\circ}$ to $7^{\circ}$. However, the hybrid carbon coating maintained superhydrophobicity even after 30

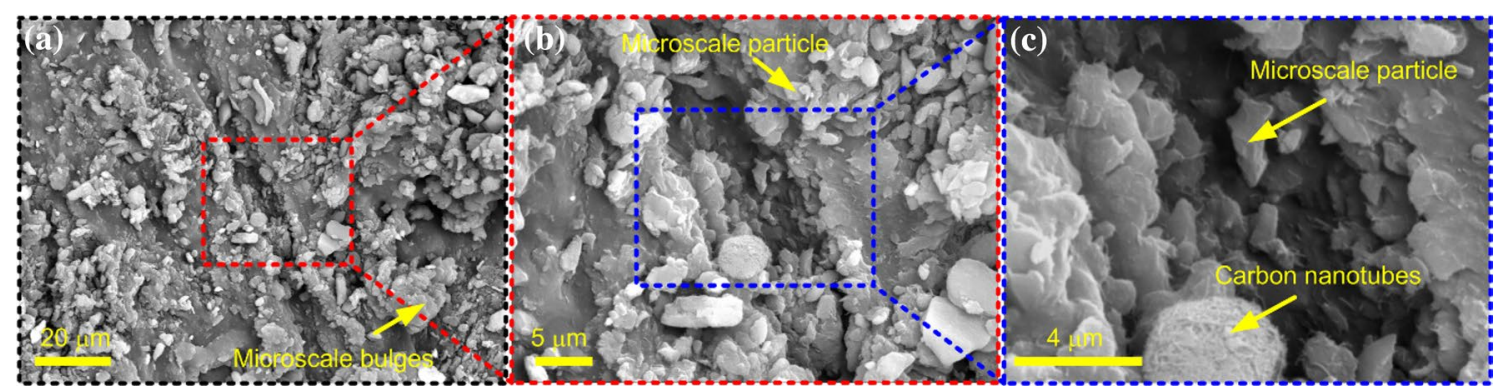

Fig. 9 The SEM image of superhydrophobic sample after sandpaper abrasions 

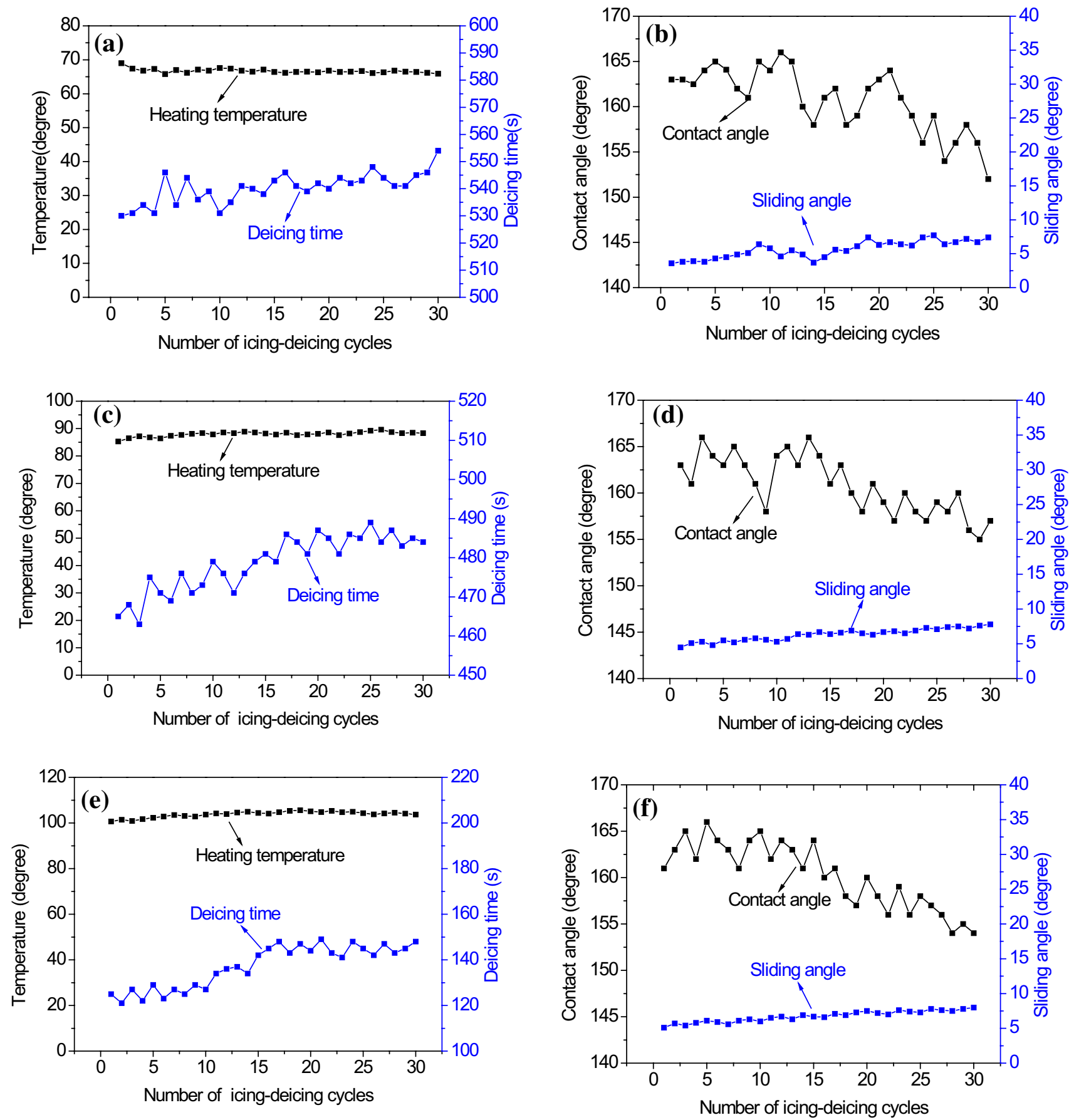

Fig. 10 The plot of heating temperature and de-icing time as a function of icing-de-icing cycles when a electrothermal, $\mathbf{c}$ photothermal, and e eletrothermal/photothermal method were utilized. The plot

icing-de-icing cycles, indicating excellent mechanical robustness. Furthermore, the icing-de-icing cycles of the sample under the photothermal condition as well as under electrothermal/photothermal synergistically strategy was tested. As shown in Fig. 10c-f, the samples retained superhydrophobicity under these two strategies.

of contact angles and sliding angles as a function of icing-de-icing cycles when b electrothermal, d photothermal, and $\mathbf{f}$ eletrothermal/ photothermal methods were utilized

\section{Conclusion}

In summary, we reported a superhydrophobic/electrother$\mathrm{mal} /$ photothermal synergistically anti-icing strategy. The superhydrophobicity was achieved based on the addition of hydrophobic fillers. The electrothermal and photothermal 
function were achieved based on the carbon nanotubes. Both electrothermal and photothermal effect could effectively melt a thick layer of ice, and the superhydrophobic surface helps the melted droplets roll off without residue. Moreover, the mechanical robustness was achieved by partially embedding the dual-scale carbon fillers into the elastomer. Thus, the prepared sample maintained superhydrophobicity after being abraded for $16.00 \mathrm{~m}$ under a $12.50 \mathrm{kPa}$ load. Furthermore, the self-healing ability was achieved using the selfhealable poly(urea-urethane) elastomer. Thus, the prepared sample can be mended by simply contacting even after being cutted into many parts.

Supplementary Information The online version contains supplementary material available at https://doi.org/10.1007/s42235-021-00093-w.

Acknowledgements This work was supported by National Nature Science Foundation of China (51977079, 51607067), the Project of Young Top Talents in Colleges and Universities of Hebei Province (BJ2021096), Youth Elite Scientists Sponsorship Program by Chinese Society for Electrical Engineering (CSEE-YESS-2017002), and the Fundamental Research Funds for the Central Universities (2020MS115, 2017MS149).

\section{Declaration}

Conflict of interest The authors declare that they have no competing interests.

Open Access This article is licensed under a Creative Commons Attribution 4.0 International License, which permits use, sharing, adaptation, distribution and reproduction in any medium or format, as long as you give appropriate credit to the original author(s) and the source, provide a link to the Creative Commons licence, and indicate if changes were made. The images or other third party material in this article are included in the article's Creative Commons licence, unless indicated otherwise in a credit line to the material. If material is not included in the article's Creative Commons licence and your intended use is not permitted by statutory regulation or exceeds the permitted use, you will need to obtain permission directly from the copyright holder. To view a copy of this licence, visit http://creativecommons.org/licenses/by/4.0/.

\section{References}

1. Bartels-Rausch, T. (2013). Chemistry: Ten things we need to know about ice and snow. Nature, 494, 27-29.

2. Liu, Y., Ma, L. Q., Wang, W., Kota, A. K., \& Hu, H. (2018). An experimental study on soft PDMS materials for aircraft icing mitigation. Applid Surface Science, 447, 599-609.

3. Liao, R. J., Zuo, Z. P., Guo, C., Zhuang, A. Y., Yuan, Y., Zhao, X. T., \& Zhang, Y. Y. (2015). Ice accretion on superhydrophobic insulators under freezing condition. Cold Regions Science and Technology, 112, 87-94.

4. Raji, A. R. O., Varadhachary, T., Nan, K. W., Wang, T., Lin, J., Ji, Y. S., Genorio, B., Zhu, Y., Kittrell, C., \& Tour, J. M. (2016). Composites of graphene nanoribbon stacks and epoxy for joule heating and deicing of surfaces. ACS Applied Materials and Interfaces, 8, 3551-3556.
5. Ma, T., Geng, L., Ding, X. H., Zhang, D. Y., \& Huang, X. M. (2016). Experimental study of deicing asphalt mixture with anti-icing additives. Constuction and Building Materials, 127, 653-662.

6. Wang, G. W., \& Guo, Z. G. (2019). Liquid infused surfaces with anti-icing properties. Nanoscale, 11, 22615-22635.

7. Nguyen, T., Park, S., \& Lim, H. (2018). Effects of morphology parameters on anti-icing performance in superhydrophobic surfaces. Applied Surface Science, 435, 585-591.

8. Wang, N., Xiong, D. S., Deng, Y. L., Shi, Y., \& Wang, K. (2015). Mechanically robust superhydrophobic steel surface with anti-icing, UV-durability, and corrosion resistance properties. ACS Applied Materials and Interfaces, 7, 6260-6272.

9. Xie, Y. H., Chen, H. F., Shen, Y. Z., Tao, J., Jin, M. M., Wu, Y., \& Hou, W. Q. (2019). Rational fabrication of superhydrophobic nanocone surface for dynamic water repellency and anti-icing potential. Journal Bionic Engineering, 16, 27-37.

10. Gao, X. Y., \& Guo, Z. G. (2017). Biomimetic superhydrophobic surfaces with transition metals and their oxides: A review. Journal of Bionic Engineering, 14, 401-439.

11. Wang, P., Li, Z. Q., Xie, Q., Duan, W., Zhang, X. C., \& Han, H. L. (2021). A passive anti-icing strategy based on a superhydrophobic mesh with extremely low ice adhesion atrength. Journal of Bionic Engineering, 18, 55-64.

12. Shen, Y. Z., Wang, G. Y., Tao, J., Zhu, C. L., Liu, S. Y., Jin, M. M., Xie, Y. H., \& Chen, Z. (2017). Anti-icing performance of superhydrophobic texture surfaces depending on reference environments. Advanced Materials Interfaces, 4, 1700836.

13. Shen, L., Ding, H. L., Cao, Q. H., Jia, W. C., Wang, W., \& Guo, Q. P. (2012). Fabrication of Ketjen black-high density polyethylene superhydrophobic conductive surfaces. Carbon, 11, 4284-4290.

14. Chu, Z. M., Jiao, W. C., Huang, Y. F., Ding, G. M., Zhong, X., Yan, M. L., Zheng, Y. T., \& Wang, R. G. (2019). FDTS-modified $\mathrm{SiO}_{2} /$ rGO wrinkled films with a micro-nanoscale hierarchical structure and anti-icing/deicing properties under condensation condition. Advanced Materials Interfaces, 7, 1901446.

15. Jiang, G., Chen, L., Zhang, S. D., \& Huang, H. X. (2018). Superhydrophobic SiC/CNTs coatings with photothermal deicing and passive anti-icing properties. ACS Applied Materials and Interfaces, 10,36505-36511.

16. Wang, P., Wei, W. D., Li, Z. Q., Duan, W., Han, H. L., \& Xie, Q. (2020). A superhydrophobic fluorinated PDMS composite as a wearable strain sensor with excellent mechanical robustness and liquid impalement resistance. Journal of Materials Chemistry A, 8 , 3509-3516.

17. Wang, P., Wang, S., Zhang, X. M., Wang, H. Q., Duan, W., Han, H. L., \& Fan, X. L. (2020). Rational construction of $\mathrm{CoO} / \mathrm{CoF}_{2}$ coating on burnt-pot inspired 2D CNs as the battery-like electrode for supercapacitors. Journal of Alloys and Compounds, 819, 153374.

18. Kulinich, S. A., Farhadi, S., Nose, K., \& Du, X. W. (2011). Superhydrophobic surfaces: Are they really ice-repellent? Langmuir, 27, $25-29$.

19. Lu, Y., Sathasivam, S., Song, J. L., Crick, C. R., Carmalt, C. J., \& Parkin, I. P. (2015). Robust self-cleaning surfaces that function when expose to either air or oil. Science, 347, 1132-1135.

20. Liu, M. M., Li, J., Hou, Y. Y., \& Guo, Z. G. (2017). Inorganic adhesives for robust superwetting surfaces. ACS Nano, 11, 1113-1119.

21. Wang, P., Chen, M. J., Han, H. L., Fan, X. L., Liu, Q., \& Wang, J. F. (2016). Transparent and abrasion-resistant superhydrophobic coating with robust self-cleaning function in either air or oil. Journal of Materials Chemistry A, 4, 7869-7874.

22. Verho, T., Bower, C., Andrew, P., Franssila, S., Ikkala, O., \& Ras, R. H. A. (2011). Mechanically durable superhydrophobic surfaces. Advanced Materials, 23, 673-678. 
23. Thakur, V. K., \& Kessler, M. R. (2015). Self-healing polymer nanocomposite materials: A review. Polymer, 69, 369-383.

24. Wu, M. C., Li, Y., An, N., \& Sun, J. Q. (2016). Applied voltage and near-infrared light enable healing of superhydrophobicity loss caused by severe scratches in conductive superhydrophobic films. Advanced Functional Materials, 26, 6777-6784.

25. Rekondo, A., Martin, R., de Luzuriaga, A. R., Cabañero, G., Grande, H. J., \& Odriozola, I. (2014). Catalyst-free room-temperature selfhealing elastomers based on aromatic disulfide metathesis. Materials Horizons, 1, 237-240.

26. Wang, P., Yao, T., Li, Z. Q., Wei, W. D., Xie, Q., Duan, W., \& Han, H. L. (2020). A superhydrophobic/electrothermal synergistically anti-icing strategy based on graphene composite. Composites Science and Technology, 198, 108307.

27. Zhou, B., Han, X. Q., Li, L., Feng, Y. Z., Fang, T., Zheng, G. Q., Wang, B., Dai, K., Liu, C. T., \& Shen, C. Y. (2019). Ultrathin, flexible transparent Joule heater with fast response time based on singlewalled carbon nanotubes/poly(vinyl alcohol) film. Composites Science and Technology, 183, 107796.

28. Pop, E., Mann, D., Wang, Q., Goodson, K., \& Dai, H. J. (2006). Thermal conductance of an individual single-wall carbon nanotube above room temperature. Nano Letters, 6, 96-100.

29. Basu, B. J., Kumar, V. D., \& Anadan, C. (2012). Surface studies on superhydrophobic and oleophobic polydimethylsiloxane-silica nanocomposite coating system. Applied Surface Science, 261, 807-814.

30. Saleema, N., Sarkar, D. K., Gallant, D. R., Paynter, R. W., \& Chen, X. G. (2011). Chemical nature of superhydrophobic aluminum alloy surfaces produced via a one-step process using fluoroalkylsilane in a base medium. ACS Applied Materials and Interfaces, 3, 4775-4781.

31. Campostrini, R., Ischia, M., \& Carturan, G. (2002). Sol-gel synthesis and pyrolysis study of oxyfluoride silica gels. Journal of Sol-gel Science and Technology, 2, 107-117.

32. Lakshmi, R. V., Bera, P., Anandan, C., \& Basu, B. J. (2014). Effect of the size of silica nanoparticles on wettability and surface chemistry of sol-gel superhydrophobic and olephobic nanocomposite coating. Applied Surface Science, 320, 780-786.

33. Errien, N., Vellutini, L., Louarn, G., \& Froyer, G. (2007). Surface characterization of porous silicon after pore opening processes inducing chemical modifications. Applied Surface Science, 253, $7265-7271$.
34. Wang, H. X., Fang, J., Cheng, T., Ding, J., Qu, L. T., Dai, L. M., Wang, X. G., \& Lin, T. (2008). One-step coating of fluoro-containing silica nanoparticles for universal generation of surface superhydrophobicity. Chemical Communications, 877, 877-879.

35. Wu, S. W., Du, Y. J., Alsaid, Y., Wu, D., Hua, M. T., Yan, Y. C., Yao, B. W., Ma, Y. F., Zhu, X. Y., \& He, X. M. (2020). Superhydrophobic photothermal icephobic surfaces based on candle soot. Proceedings of the National Academy of Sciences, 117, 11240-11246.

36. Yin, F. H., Farzaneh, M., \& Jiang, X. L. (2016). Laboratory investigation of AC corona loss and corona onset voltage on a conductor under icing conditions. IEEE Transactions on Dielectrics and Eletrical Insulation, 23, 1862-1871.

37. Wang, D. H., Sun, Q. Q., Hokkanen, M. J., Zhang, C. L., Lin, F. Y., Liu, Q., Zhu, S. P., Zhou, T. F., Chang, Q., He, B., Zhou, Q., Chen, L. Q., Wang, Z. K., Ras, R. H. A., \& Deng, X. (2020). Design of robust superhydrophobic surfaces. Nature, 582, 55-59.

38. Zhou, Y. Y., Ma, Y. B., Sun, Y. Y., Xiong, Z. Y., Qi, C. H., Zhang, Y. H., \& Liu, Y. Q. (2019). Robust superhydrophobic surface based on multiple hybrid coatings for application in corrosion protection. ACS Applied Materials and Interfaces, 11, 6512-6526.

39. Wang, X. Y., Li, M. J., Shen, Y. Q., Yang, Y. X., Feng, H., \& Li, J. (2019). Facile preparation of loess-coated membranes for multifunctional surfactant-stabilized oil-in-water emulsion separation. Green Chemistry, 21, 3190-3199.

40. Chen, F. Z., Song, J. L., Lu, Y., Huang, S., Liu, X., Sun, J., Carmalt, C. J., Parkin, I. P., \& Xu, W. J. (2015). Creating robust superamphiphobic coatings for both hard and soft materials. Journal of Materials Chemistry A, 3, 20999-21008.

41. Song, J. L., Zhao, D. Y., Han, Z. J., Xu, W., Lu, Y., Liu, X., Liu, B., Carmalt, C. J., Deng, X., \& Parkin, I. P. (2017). Super-robust superhydrophobic concrete. Journal of Materials Chemitry A, 5 , 14542-14550.

42. Tian, X. L., Verho, T., \& Ras, R. H. A. (2016). Moving superhydrophobic surfaces toward real-world applications. Science, 352, $142-143$.

Publisher's Note Springer Nature remains neutral with regard to jurisdictional claims in published maps and institutional affiliations. 